\title{
Research on Micro-marketing Communication of Organic Tea
}

\author{
Liu Luxing, Wu Shengyi
}

Fujian Agriculture and Forestry University, Fujian, Fuzhou, China

luxing8@163.com

Keywords: organic tea, marketing communication, micro-marketing communication.

\begin{abstract}
Based on the recent marketing communications of organic tea, the paper analyzes the problems and selling effect, for exploring some new ways in this field. The paper analyzes marketing communication from two aspects, consumers and products. Based on the factors, the paper establishes a characteristic marketing mode, micro-marketing communication to promote the sales volume and market share.
\end{abstract}

\section{Introduction}

Organic tea is the tea which is produced with the traditional cultivation way. In China, the enterprises of organic tea need to be identified by qualified institutions to have the qualification of producing, processing and selling organic tea. The characteristics of the products are green and no pollution. It is forbidden to use herbicide, fertilizer and pesticide in production process, and it applies biological and artificial method for agricultural production. The present marketing communication of the organic tea has some problems, which hinders the development of domestic market. And the problems are that the communication channels are narrow, the arrival rate of the specific media for the target population is low, the frequency of specific customers being exposed under information is low and the quality value to be exposed by specific media is low. The paper starts from the marketing communication of organic tea, and analyzes the existing problems. And combined with the characteristics of the products and the features of the consumers, the paper establishes a new marketing communication mode meeting the features of organic tea, micro-marketing communication.

\section{The Status and Problems of Marketing Communication of Organic Tea}

The problems of personnel marketing and word-of-mouth marketing is that the consumers are limited. The personnel only can communication with the customers in the organic tea shop with one-to-one way, which is difficult to communicate with the potential customers and limits the development of later customer maintenance and after-sale service. According to propagation model theory, the communication of a brand is continuous and lasting, which goes through the following stages, consumer cognition stage, consumer emotion input stage and consumer purchase stage. The formation of brands requires repeated information disclosure, consumer acceptance and consumer cognition, which can receive higher intervention in the heart of the consumers. The repeatability and durability of word-of-mouth and personnel marketing is low, so it is not favorable for the communication of brands and the propagation of organic tea culture.

The problem of advertisement marketing is that the cost is higher and the constraint of finance is evident. The selection, design and decoration of physical stores needs to reflect the strength and style of the enterprises, so the chain-store operated organic tea stores are generally in the local prosperous streets and require the investment of 300000 yuan at least (the specific investment should depend on the scale of the stores and the grade of the tea). The scale of the stores is generally larger than 80 square meters, and the stores should have 6 professional salesmen. In recent years, with the increase of the rent and the wage of personnel, the operation cost of physical stores has kept rising, and some chain enterprises have been closed some stores. Therefore, no matter paper media advertisement or outdoor advertisement, the selling expense brings financial burden for the enterprises. And for financial process, the selling expense is 
directly counted into the current profit and loss, which directly influences the current financial profit, and has influence on the current profit of the enterprises. The audiences of the advertisement are dispersed and popular, so it lacks of pertinence in the communication process, which makes quality value low.

The problem of sales promotion is that it is not consistent with the product positioning of organic tea. The product positioning of organic tea is to attract the people who concerns zoology, health and environment health. The production and processing technique of organic tea includes more artificial cost, organic fertilizer cost and tea garden management cost, so the price is higher than the conventional tea. The positioning of the products determines the target consumers of organic tea should have higher payment ability, which is different from the conventional tea customers which are very sensitive to the price. Generally speaking, the communication technique of sales promotion is that it plays a better role for the customers who are very sensitive to the price in the marketing process of conventional tea. In the field of organic tea, the conventional ways including promotion, coupon, discount and gift can weaken the brand value and brand image of organic tea, which is not good for image positioning of high-end organic tea products.

\section{Establishment of New Marketing Communication Technique of Organic Tea---Micro-marketing Communication}

With the development of information technique, new marketing communication technique emerges, which has important significance for the propagation and development of organic tea. Traditional marketing communication techniques include newspaper propagation, leaflets, TV advertisement, interstitial advertisement of websites and personnel sales. With the development of information technique, there is micro-marketing, micro-blog and WeChat. Micro-marketing is the promotion activity of using micro-blog, WeChat platform and public WeChat platform.

For the above requirements for the marketing communication of organic tea, and the problems that the awareness of the consumers is low, the intervention of the consumers for organic tea is low and marketing expense is high, the micro-,marketing communication of organic tea should be developed from the following aspects.

\section{Increasing exposure rate of information and improving intervention degree of consumers.}

At present, most users of smart phones install the software of WeChat and microblog, which makes then refresh and look up the latest activities and the product information. In order to improve intervention degree of consumers, the visibility of two-dimension code should be added. For example, the twodimension code is printed on brochure, websites, outdoor advertisement, name cards, gifts and tea set of organic tea enterprises. And the consumers can be encouraged to brush the two-dimension code by the way of giving gifts, for improving the attention of enterprises. After owning some users, the content of the later marketing of WeChat and microblog should be attractive to retain the existing customers. The pushed information content should include the hot information which attracts the attention of consumers. In order to highlight the core product culture, health, ecology and no pollution, the pushed content should include the topic about health, keeping in good health and environmental protection, for improving the green-consumption consciousness of consumers, and improving the product cognition degree of organic tea and popularity of organic product knowledge. For the cognition degree of brands, the products can be combined with producing area, which means to push organic tea new relating to Anxi, pictures of tea base and processing information of tea. The soil, air, temperature and humidity of agricultural products makes Anxi have unique competition advantages, which promotes the competition of organic tea brand. Video, picture and word can be used to describe and display the originally ecological production base of organic tea in Anxi, which can make the users directly feel green culture of organic tea. The pushing time and frequency needs to be designed. The consumers of organic tea generally have fixed job and are busy in the working time. In the initial stage of micro-marketing promotion, it is not suitable to push with high frequency. It can be pushed twice in a week. And it is pushed after work and on the weekends, which can ensure that the target consumers have enough time to read the information. 


\section{Establishing friend circle and developing deep circle marketing.}

The enterprises of organic tea should establish a marketing matrix of friend circle to make that the marketing way and the later management and communication of customers form an effective system. Deep penetration in customer group can find more potential consumers. WeChat friend circle is based on Facebook, a social network in America. It is established based on connections, and a virtual online community is established. Therefore, the marketing communication of organic tea can make specific marketing with the help of natural connections. By analyzing the target customers of organic tea, drinking tea is the fixed habit of a specific circle. Therefore, only finding the circle by friend circle and making deep marketing can achieve better effect. The enterprises of organic tea need to make the relation chain of social networking service of selling organic tea by friend circle. It makes communication and interaction by pushing product information and public relationship activities, for maintaining and consolidating relationship basis. The information to be transferred in the friend circle is real and credible, and the members of the friend circle generally have the same hobby and consumption tendency. Therefore, propagating the culture of organic tea in friend circle is correct, credible, private and influencing, which has better marketing effect.

Opening customer service function of WeChat platform and strengthening the interaction of customers and enterprises.

The later customer relationship management should highlight that the microblog is new, the forum retains customers and WeChat refreshes customer service. The later tracing service should be made through forum and WeChat customer service. The organic tea enterprises can arrange full-time personnel to trace by establishing public platform account of WeChat, and directly push the valuable information to the users on the platform. For example, the organic tea enterprises can try establishing WeChat platform customer service, and select phone addition as signal test. When the users input the characters according to the prompt given by the system, the system can send the prompt of reply in real time. The users can conveniently inquire brand production, brand culture and communication information of enterprises, especially the information about product classification, production series, parameters and market price. After the users make horizontal comparison with the same products, the users can purchase the product on the phone, and the purchasing process is easy and saves time. Therefore, improving the interaction of the customer service of enterprises with the users not only can improve the brand value and organic culture of organic tea enterprises, but also can promote the market sales volume of organic tea.

\section{Combining WeChat platform and adding the function of mobile remote payment.}

When the marketing platform of WeChat guides the consumers to purchase the products and communicate with customer service, the mobile remote payment function is to solve the payment of consumers. The Mobile Consumer Report in 10 countries shows that the owning rate of smart phones and penetration rate of new technological application software is high in China and achieves 66\%, which is only send to that in Korea (67\%), and is higher than that in Australia (65\%), Italy (62\%), England (61\%) and America (53\%). The popular commercial application of mobile remote payment in China is shopping (34\%), the third party payment (34\%) and bank client payment (30\%). Especially the technique and credibility of the third-party payment is guaranteed by the capital regulators of the third party, which solves the problem that the information of buyer and the seller is not asymmetric. In the investigation of consumers, 73\% of consumers agree that shopping has become the most popular third-party payment function by the consumers. From the percentage of support rate of consumers in Figure 1, we can see that the third-party payment has evident advantages for easy input, wide business coverage and rich promotional information. So in the payment link of micro-marketing communication, the third-party payment procedure of smart phones should be developed greatly to promote purchasing experience of consumers and convenience of payment. By the combination of WeChat and mobile payment function, the interface operation of selection, purchase and payment is easy. With the technical support, five passport protection functions are set from logging in to payment, which ensures the security of transaction. 


\section{References}

[1] Philip Kotler, Marketing Management [M], Beijing, China Renmin University Press, 2001:518-522.

[2] Jiang Hanchun, Tea Marketing [M], Beijing, China Agriculture Press, 2010: 63-69.

[3] Zhou Guoqing, Cao Shisheng, Marketing theory of microblog publish [J], Modern Communication, 2013(11): 100-101.

[4] Wang Yi, WeChat marketing and operation: strategy, method skill and practice [M], Beijing, China Machine Press, 2013:167-177.

[5] Xia Yuhe, Structure and mechanism of microblog interaction [J], News and communication research, 2010(04):66-67.

[6] Meng Yuhui, Reconstruction of confidence of food consumers under microblog communication [J], Modern Communication, 2013(02) : 52-54.

[7] Nielsen Company, More than $86 \%$ of Chinese consumers increase/try using mobile remote payment App. [EB]. http://cn.nielsen.com/site/documents/china-cn-mobile-payments-pr-12-26-13.pdf.

[8] Wu Zhidan, Weng Baiqi, Development trend of organic tea in China and countermeasures [J], Chinese Agricultural Science Bulletin, 2009(02): 246.

[9] Guo Na, Liu Dongying, Analysis on comparison of trade mode of agricultural products on the network [J], Issues in Agricultural Economy, 2009(03) : 76-80.

[10] Song Xinhua, Exploration of new organic agriculture mode [J], World Agriculture, 2013(05) : 45-46. 